\title{
The Design of Visual Communication for Intangible Cultural Heritage in Product Form
}

\author{
Wei-Bo Huang* \\ Education Technology Center, Experimental Teaching Center \\ Guangdong University of Foreign Studies \\ Guangzhou, China \\ 172564946@qq.com
}

\section{Wen-Xin Liang}

School of Accounting

Guangdong University of Foreign Studies

Guangzhou, China

\section{Ge-Ling Lai}

School of Journalism and Communication

Guangdong University of Foreign Studies

Guangzhou, China

\author{
Han-Dun Xiang \\ School of Art \\ Guangdong University of Foreign Studies \\ Guangzhou, China
}

Xiao-Dan Li

School of English Education

Guangdong University of Foreign Studies

Guangzhou, China

Yin Lin

School of Public Administration

Guangdong University of Foreign Studies

Guangzhou, China

\begin{abstract}
The socio-economic development and the deepening of globalization have brought many difficulties to the inheritance and protection of intangible cultural heritage. This study analyzes the visual communication and the protection and predicament of intangible cultural heritage by means of literature, comparison and induction. In order to explore new ways to protect and inherit intangible cultural heritage in the new era, the study combines the intangible cultural heritage with the current relatively novel visual communication technology and provides a new direction for the formal design of intangible cultural heritage products. The application results show that the study is conducive to protecting the intangible cultural heritage left over by our ancestors.
\end{abstract}

Keywords-Intangible cultural heritage; Visual communication; Innovation design

\section{INTRODUCTION}

Visual communication, as is implied, is a form of artistic design that uses human eyes as a medium to convey information to people through eyes, such as text and graphics to convey information to the audience. It can be seen that books, newspapers and mobile phone clients are carriers of visual communication in daily life. The invention and popularization of computers have brought dramatic changes to people's lives to a great extent. The birth of the Internet has directly and forcefully promoted the new forms of communication and media which are based on the network. The use of new materials and new media provides more possibilities for visual communication design, and the design field is gradually moving towards multi-dimensional development. Visual communication design is no longer a single, flat thing but gradually begin to integrate with other art fields [1]. Traditionally, visual communication design works are mostly graphic works, mainly using print as the technical means of creation and propaganda, and the paper is the carrier of information dissemination. While technological innovation provides a broader space for the development of visual communication design, beginning to involve other design art majors closely related to vision. The field is heading for the direction of multi-media development [2].

Foreign researches on cross media development of visual communication design are relatively mature. Although domestic research has quantitative advantages, most of them are one-sided, lack of pertinence, and relatively lack of indepth theoretical analysis. Especially, many of the latest design ideas have not been included in the scope of research, and have not formed a complete system. Although many designers in China have begun to try to add Chinese culture as a visual element to visual communication design, it is only the attempt of a few people, and has not yet formed a real innovation in the ideological trend, and it is not applicable to all types of visual communication design [3]. 


\section{VISUAL COMMUNICATION TECHNOLOGY}

The development of visual communication technology has gone through three stages. When the visual communication technology was raised at the first time, designers mainly display their works in hand-painted way, which was the period of paper media. With the invention of computer and the popularization and application of computer software technology, image media began to be used in visual communication design, and became a new form of vision. This period was the period of image media. During this period, the technology was mainly used in the aspect of effect display, such as web page design, exhibit design and so on. With the further integration of digital media and visual communication design, more realistic three-dimensional visual performance, dynamic effects are favored by designers and audiences, visual performance has entered the digital media performance period [4], greatly expanding the application field of visual technology.

Visual communication makes the presentation of information more intuitive and effective, and it is easier to get people's attention in this era of scarce attention, which is conducive to the dissemination of works design. Nowadays, with the maturity of computer technology, visual communication is applied in more and more fields, and its limitations are less and less. Visual communication has a certain extension in space, and its connotation is more abundant. In terms of the demand of cultural communication, visual communication is more matched with it [5].

\section{OVERVIEW OF INTANGIBLE CULTURAL HERITAGE}

\section{A. The Meaning and Current Situation of Intangible Cultural Heritage}

The intangible cultural heritage covers a wide range of areas. The UNESCO Convention on the Protection of the intangible cultural heritage recognizes that the intangible cultural heritage includes various practices, such as performances, manifestations, knowledge systems and skills and related tools, objects, crafts, cultural sites and so on [6].

With the development of social economy in our country, people begin to pay attention to spiritual satisfaction because of the great material richness. While the introduction of foreign culture enriches the development of our culture, it also has a certain negative impact on our local excellent culture. The government also pays more attention to the protection of cultural heritage. In 2005, the State Council first proposed to protect intangible cultural heritage, and later the first China intangible cultural heritage exposition was successfully held in Jinan in October 2010. By 2017, there are 39 projects of intangible cultural heritage in China having been recognized as the world-class intangible heritage sites, ranking first in the world in total [7].

\section{B. The Dilemma of the Inheritance and Protection of Intangible Cultural Heritage in China}

At present, economic globalization is an irresistible trend of development. Under the background of economic globalization, those countries that are closed themselves will be abandoned by the others. We must open our doors to the whole world, which also means that foreign cultures will enter our country. Under such a background, the protection of intangible cultural heritage has two levels of significance. First, at the level of the international community as a whole, the protection of intangible cultural heritage is not a matter of one country only, but the common wealth of all mankind [8]. Protecting heritage shows a responsible attitude towards all mankind, which contributes to the formation of a vibrant and rich human culture. General Secretary Xi Jinping put forward the idea that we should jointly build a community of life and regard the whole earth as the common home of all mankind. The protection of excellent culture is no longer a narrow proposition, which involves not only the destiny of our own nation, but also the common interests of all mankind. Standing at the national level, China's rich intangible cultural heritage is a gift of history and a precious treasure of 56 ethnic groups that have survived for thousands of years. These cultural heritages are an important part of Chinese culture. Spiritually, they give Chinese a deep sense of belonging, which is our cultural self-confidence to let us stand in the world's national forest. Materially, they can be transformed into cultural products with great economic benefits and stimulate the development of local economy. And our culture promotes love and tolerance, advocating the harmony of interpersonal relationships. Therefore, the protection of intangible cultural heritage has practical significance in maintaining social harmony and stability [9].

In the context of economic globalization, foreign cultures have entered our country, which creates opportunities for the integration and innovation of our culture, as well as bring pressures for the development of our culture. In recent years, Western festivals such as Halloween and Christmas have been highly sought after by people. On the contrary, traditional festivals such as Chinese Spring Festival and Dragon Boat Festival have been neglected, which has aroused social concern and reflection of scholars. With the development of modernization and urbanization, more and more rural people have entered cities. Rural area is the main place of intangible cultural heritage, also the breeding place of farming culture and the natural environment on which folk culture depends. But rural areas have undergone drastic changes. The popularization of television and Internet has greatly make people get access to the information more easily, resulting in the increasingly difficult survival of folk artists, which is not conducive to protecting the integrity of national "cultural memory", increasing the probability of national "cultural memory" being forgotten. What's worse, it will seriously threaten the long history of the Chinese nation's oral and intangible cultural heritage [10]. 
IV. VISUAL COMMUNICATION APPLIED TO PRODUCT DESIGN OF INTANGIBLE CULTURAL HERITAGE

\section{A. The Necessity of Visual Communication Applied to Product Design of Intangible Cultural Heritage}

Nowadays, the information disseminated on the Internet is expressed in various ways, and it is difficult to get people's attention to a single static pattern or text information. In order to make the information better accepted by the audience, visual communication began to integrate a variety of ways of visual expression, with creativity as the core and dynamic as the dominant. In the era of media convergence, visual communication technology has shown a new feature of humanmachine interaction and interaction design. The visual communication design, which is developing in the direction of diversification, firstly uses the shape and expression of the space [5]. The original two-dimensional plane space is the traditional form of information transmission. In addition, information can also be conveyed in multi-dimensional space. In the process of switching the rich spatial levels, it can further show the attractiveness of information. This requires the integration of different techniques and artistic techniques in visual communication to achieve the best aesthetic design effect. But designers should always bear in mind that the reality is the most important foundation in visual communication design. Designers should create based on authenticity, no matter what form of expression they adopt and what kind of post-effect they add. Therefore, the application of visual communication in intangible cultural heritage should first be based on the characteristics of intangible cultural heritage itself and determine the form of visual expression according to its unique features.

\section{B. Feasibility of Visual Communication Applied to Intangible Cultural Heritage Product Design}

With the development of computer technology, the version of digital technology is changing rapidly. At present, besides digital visual design software such as Photoshop and Adobe Premiere, which are used to embellish pictures, videos and other information forms, 3D technology is becoming more and more mature. What's more, its application in design is also increasing [9]. After choosing the visual communication mode of intangible cultural heritage products, the preliminary design is relatively simple. On this basis, the relevant digital visual design software can be used to add rendering effect. Photoshop can modify image defects. Adobe Premiere series software can make pictures or video clips into gorgeous views. Frequency, 3D printing technology can show three-dimensional effect, using plane, three-dimensional and spatial elements synthetically. It can make text, graphics and patterns dynamic in three-dimensional or even multi-dimensional space so that people can be immersed in it. These digital technology rendering can integrate a variety of sensory experiences and make the final work more attractive.

\section{APPLICATION DESIGN}

\section{A. Combine Visual Communication with Intangible Cultural Heritage Product Design}

The organic combination of visual communication technology and intangible cultural heritage is undoubtedly an innovative application of visual communication technology. The protection and inheritance of intangible cultural heritage encounter difficulties in the information age. The creative design of product form is carried out by using computer technology to stimulate the vitality of intangible cultural heritage.

The organic combination of visual communication technology in the product design of intangible cultural heritage not only puts forward certain rigid requirements for computer technology, but also needs to deeply excavate the human light contained in intangible cultural heritage. The intangible cultural heritage itself is an inanimate thing, so blindly displaying itself will not fully express its intrinsic value. We need to fully understand the historical stories and unique charm behind the intangible cultural heritage, and then use visual communication technology to show it in the form of visual reflection. The intangible cultural heritage has the characteristics of traditional culture. If it is integrated into the process of visual communication, the works themselves will have more cultural flavor and characteristics. In this era of no lack of creativity, if the works have no unique points and farreaching cultural connotation and significance, they will soon be submerged in the product wave and even be forgotten by the audience. Our country's intangible cultural heritage has profound national characteristics and cultural elements. If we use the integrate visual communication technology to fully display the historical details and humanistic color of intangible cultural heritage, rather than just making it into a passionless video, we will make the work full of Chinese characteristics, and can be more deeply impressed by the masses.

\section{B. The Process Framework of Visual Communication Applied to the Design of Intangible Cultural Heritage Products}

On this basis, this paper explores the mode of visual communication creative design of intangible cultural heritage in product form, and puts forward the process framework of visual communication design, which is divided into four steps, as shown in Figure 1. 


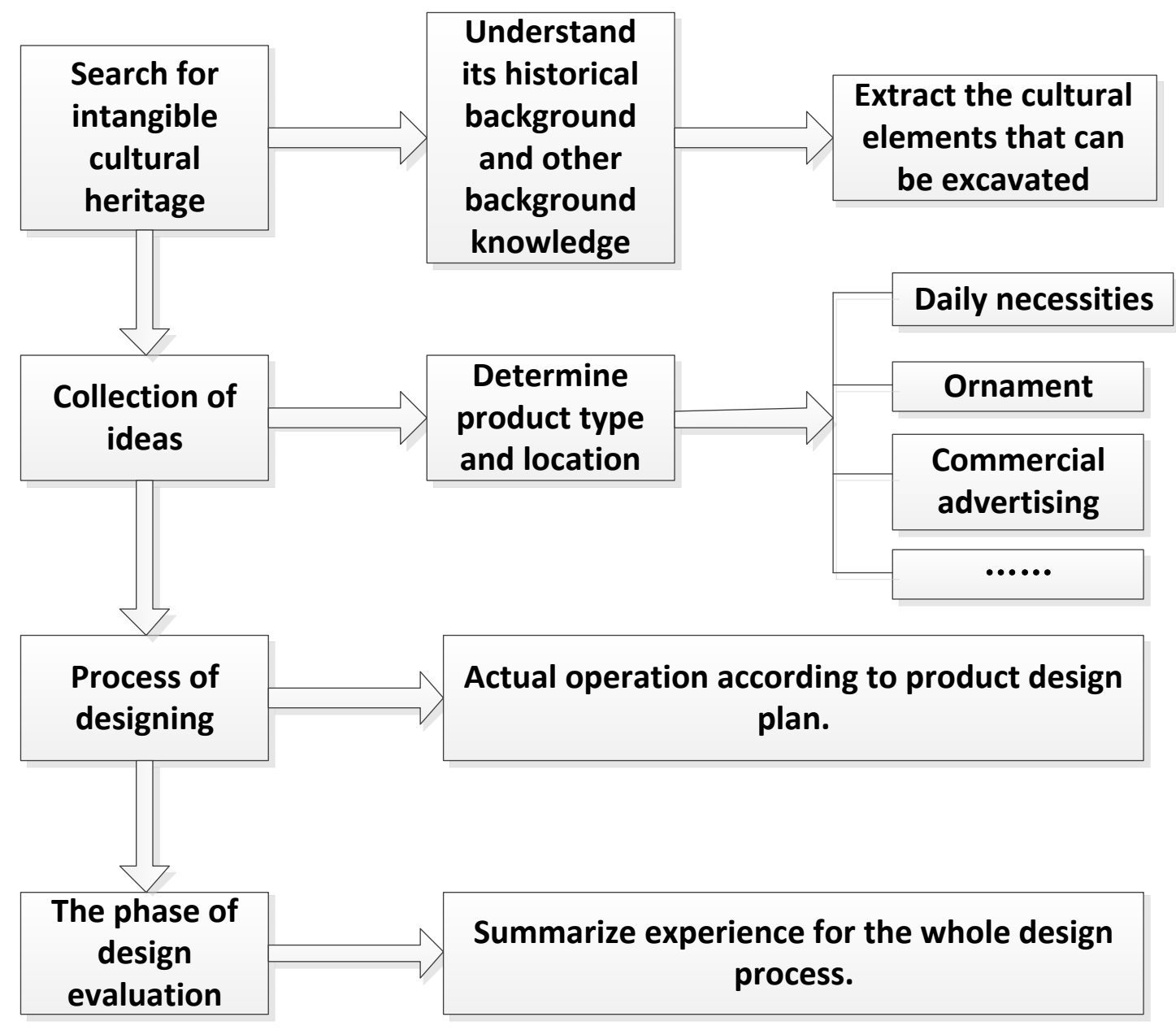

Fig.1. Creative design process framework of intangible cultural heritage in the form of product visual communication

The first step is the process of searching for intangible cultural heritage. There are many intangible cultural heritages in our country. We should determine the specific design objects at the beginning. Firstly, through on-the-spot investigation of intangible cultural heritage, we can find its historical origin and development. Visiting its inheritors, collecting their stories, and understanding the relevant knowledge will help us to learn from them. Cultural elements are extracted to provide ideas for further design. The second step is to collect design ideas on the basis of collecting data. That is, to acquire the cultural elements of intangible cultural heritage in these stories, to determine the category of products, and to form a draft product, so as to determine the way of product presentation, style design, product function and so on. Different presentation methods and style design will produce different effects. Designers should grasp the original intention of product design, carefully consider the product deduction and design style in order to better suit the characteristics of the product. The third step is to standardize product design within the framework of product draft, to form a detailed and feasible product design drawings, and to provide the necessary parameters for product production. In the standardized design process, we should make appropriate adjustments to the product draft according to the actual technological level. The last step is the design evaluation. When the product design is completed, the whole design process is reviewed and summarized, which is conducive to the formation of experience and provides data reference for similar peer research.

\section{CONCLUSIONS}

China's long history and the people of all nationalities' practice in real life have created a rich intangible culture, which contains incalculable economic and cultural benefits. In the era of big data, the rapid development of computer technology provides technical support for the innovative inheritance and development of intangible cultural heritage. It also provides a new way to activate and display the unique value and deep vitality of intangible cultural heritage. This study explores the organic combination of intangible cultural heritage and visual communication technology, explores the feasibility of using visual communication technology in product design of intangible cultural heritage, and designs the process framework of visual communication creative design of intangible cultural heritage in product form. After practice, the process design is scientific. The integration of intangible cultural heritage and visual communication creative design will further explore the feasibility and new path of intangible cultural heritage value, bringing new ideas for the inheritance of intangible cultural heritage, and provide a new perspective for related computer technology development. 


\section{REFERENCES}

[1] R. Haines, and J. E. C. Mann, "A new perspective on de-individuation via computer-mediated communication," European Journal of Information Systems, vol. 20, pp. 156-167, Feburary 2011.

[2] Q. H. Qin, and S. O. Arts, "On visual communication modes for Chinese-style fashion: a case study of Chinese cheongsam," Journal of Nanning Polytechnic, 2016.

[3] M. Agrawala, W. Li, and F. Berthouzoz, "Design principles for visual communication," Communications of the Acm, vol. 54, pp. 60-69, April 2011

[4] J. W. Huang, "Research on the computer graphic design and visual communication design," Advanced Materials Research, 1055, pp. 342345, 2014.

[5] O. Schroth, J. Angel, S. Sheppard, and A. Dulic, "Visual climate change communication: from iconography to locally framed $3 \mathrm{~d}$ visualization," Environmental Communication, vol. 8, pp. 413-432. April 2014.

[6] M. Alivizatou-Barakou, A. Kitsikidis, F. Tsalakanidou, K. Dimitropoulos, C. Giannis, and S. Nikolopoulos, "Intangible cultural heritage and new technologies: challenges and opportunities for cultural preservation and development," Springer International Publishing, 2017.

[7] J. H. Bie, and L. Bao-Er, "A literature review on the protection and utilization of china's intangible cultural heritage," Tourism Forum, vol.17, pp. 603-609. July 2008.

[8] E. F. Katsouli, "Innovative technologies for intangible cultural heritage education and preservation: the case of i-treasures," Personal \& Ubiquitous Computing, vol. 21, pp. 1-13, Febuary 2017.

[9] L. Viinikkala, L. Yli-Seppälä, O. I. Heimo, S. Helle, L. Härkänen, and S. Jokela, "Reforming the representation of the reformation: Mixed reality narratives in communicating tangible and intangible heritage of the protestant reformation in Finland," International Conference on Virtual System \& Multimedia, pp.1-9, IEEE, 2017.

[10] M. J. D. Barrio, M. Devesa, and L. C. Herrero, "Evaluating intangible cultural heritage: the case of cultural festivals," City Culture \& Society, vol. 3, pp. 235-244. April 2012. 